\title{
THE REPRODUCTIVE STATUS OF FEMALE MINK, MUSTELA VISON, RECORDED AS 'FAILED TO MATE'
}

\author{
C. E. ADAMS \\ Agricultural Research Council, \\ Unit of Reproductive Physiology and Biochemistry, University of Cambridge*
}

(Received 30th November 1972)

The mink has a short, well-defined breeding season extending from February to March. On fur farms in Great Britain, as in Scandinavia and North America, the first matings usually take place about 10th March. Various mating systems are employed, all of which tend to involve the use of the same or different males at intervals; for example, mating on Day 0 (male A), Day 1 (male B), and Days 8 and 9 (male C). Normally, ovulation is induced by the stimulus of coitus which it follows after 36 to $37 \mathrm{hr}$ (Hansson, 1947) or after approximately $48 \mathrm{hr}$ according to Enders (1952). Enders also reported that many females ovulated following only brief contact with a male during which the female was not seized nor intromission attempted.

Each breeding season, a proportion of females fail to mate: Enders estimated 10 to $30 \%$ but a recent survey (Ministry of Agriculture, Fisheries and Food), based on 89,083 mink, showed a much reduced figure of $5.41 \%$. On larger farms, it is common practice to pelt out any females that have not mated by the end of March. Earlier this year, the opportunity was taken to examine a group of such females in an attempt to establish the cause of their reproductive failure.

Forty female mink, including equal numbers of the four colour phases, Dark, Pastel, Pearl and Silverblue, were collected from Solitaire Furs Ltd, Brome, Suffolk, after slaughter on 5th April 1972. The animals, aged 1 to 4 years, included twenty-four nulliparae, six primiparae, and ten which had each produced two or three litters. The mean size of their thirty litters was $6 \cdot 17$ (4 to 12). At Brome, where over 5000 breeding females are maintained, the mating procedure involves, 'attempting to present all the females in the first week of the season beginning 5 th March. Females which do not mate first time are presented daily with different males for the first week and thereafter every few days'.

Examination of the genital tracts was carried out under laboratory conditions in Cambridge. Apart from noting the general condition of the tract, the numbers of corpora lutea and of implantations, if any, were recorded. A Zeiss stereomicroscope $(\times 10)$ was found helpful for counting the corpora lutea. If no implantations were visible, the uterine horns were each flushed with $2 \mathrm{ml}$ physiological saline. The flushings, collected into punted watch glasses, were examined microscopically $(\times 20$ to $\times 80)$ for the presence of eggs,

* Postal address: 307 Huntingdon Road, Cambridge CB3 0JQ. 
which were counted and photographed. The ovaries and a portion of the uterus were fixed in Bouin's fluid for histological purposes.

The general physical condition of all the mink was excellent and, except for one case of infantile uterus, the genitalia were well-developed and normal in appearance.

Corpora lutea were present in thirty-six of the forty animals: the four without corpora lutea were all Silverblue and included three nulliparae. The mean numbers of corpora lutea were 19.2 (15 to 25 ), 17.2 (9 to 23 ), 18.3 (11 to 25 ) and 15.8 (11 to 24) for the four colour phases. Amongst the animals with corpora lutea, six were found to be pregnant, including three with eight, eight and fourteen implantation sites and three with one, seven and eleven blastocysts, respectively. All except four of the remaining thirty animals yielded degenerate eggs, of which more than 200 were recovered. A high proportion of these eggs had fragmented and many were surrounded by an extra layer, about $15 \mu \mathrm{m}$ thick. In some animals, every egg possessed this layer (Pl. 1, Fig. 1) whilst in others, only some eggs were affected (Pl. 1, Figs 2 and 3), possibly due to differences in the eggs' ages, since two crops may have been ovulated 1 week or more apart. Since the layer is absent from eggs or blastocysts which have only recently entered the uterus, a uterine origin is indicated. In the ferret, unfertilized eggs may also become embedded in a mass of 'tubal and/or uterine secretion' (Wu \& Chang, 1972). This condition was depicted but not commented upon by Chang (1957).

The importance of psychic factors in ovulation in the mink (Enders, 1952) is underlined by the present investigation in which $90 \%$ of the animals examined had corpora lutea with the majority having ovulated on more than one occasion, as reported by Kler (1971).

The occurrence of some $(15 \%)$ pregnant females indicates that a few matings must have taken place unobserved. It is known that pregnancy may result from an intromission as brief as 2 min if preceded by psychic stimulation (Enders, 1952). In general, however, matings of shorter duration than $12 \mathrm{~min}$ are considered to lead to reduced fertility (Venge, 1956). Normally, the length of copulation varies from a few minutes to several hours; Hansson (1947) found that the average length of 227 matings was $64 \mathrm{~min}$.

Over the 5-year period, 1968-72, the proportions of females recorded as 'failed to mate' at Brome were $2 \cdot 30 \%, 2 \cdot 95 \%, 3 \cdot 64 \%, 3.38 \%$ and $3.36 \%$. In practice, this means that in 5000 females, of which $50 \%$ are triple mated, $30 \%$ double mated, and $20 \%$ single mated, probably not many more than twenty-five matings out of 11,500 pass unobserved.

Mink farmers regard the 'failed to mate' category as most troublesome because so much time and effort are expended on it. The present results suggest that the problem is largely a behavioural one because in other respects repro-

EXPLANATION OF PLATE 1

Figs 1, 2 and 3. Groups of unfertilized eggs recovered from the uterine horns of three mink pelted on 5th April 1972 for failure to mate. Many of the eggs have fragmented, and some show the extra layer surrounding the zona pellucida. The eggs in Fig. 1 present a uniform appearance, whereas those in Figs 2 and 3 appear to comprise two distinct groups, suggesting they originated from two different sets of ovulations. Fig. 1, × 150; Figs 2 and $3, \times 125$. 
PLATE 1

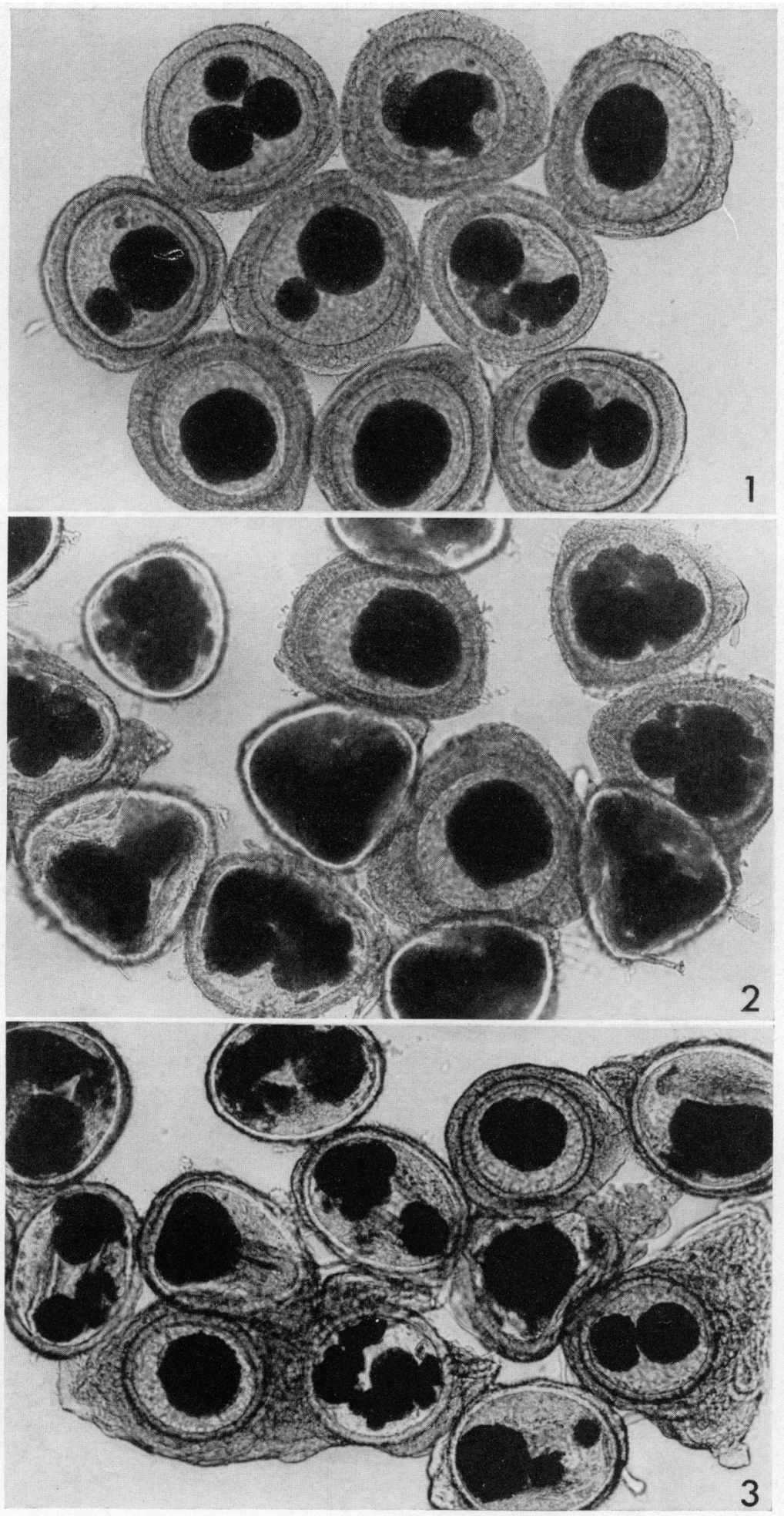


ductive function appears quite satisfactory. If ovulation is so readily induced, it is essential to obtain a mating within $24 \mathrm{hr}$ of the first exposure to ensure fertilization. When ovulation has occurred, the female mink may resist mating for several days until a new wave of follicles has developed: normally, an interval of at least 5 to 6 days is required before ovulation will recur (Hansson, 1947). Recognition of these facts should permit a more rational approach in practice.

I am deeply indebted to Mr R. Forman of Birds Eye Foods Limited for his help in procuring the mink as well as for supplying details of their breeding.

\section{REFERENCES}

CHANG, M. C. (1957) Natural occurrence and artificial induction of parthenogenetic cleavage of ferret ova. Anat. Rec. 128, 187.

ENDERs, R. K. (1952) Reproduction in the Mink (Mustela vison). Proc. Am. phil. Soc. 96, 691.

Hansson, A. (1947) The physiology of reproduction in mink (Mustela vison, Schreb.) with special reference to delayed implantation. Acta zool., Stockh. 28, 1.

KLER, R. V. (1971) Some characteristics of ovulation in the mink. Cited in Anim. Breed. Abstr. (1972) 40, 551. Abstr. No. 3486.

Venge, O. S. W. (1956) Experiments on forced interruption of the copulation in mink. Acta zool., Stock. 37, 287.

Wu, J. T. \& Chang, M. G. (1972) Effects of progesterone and oestrogen on the fate of blastocysts in ovariectomized pregnant ferrets: a preliminary study. Biol. Reprod. 7, 231. 